\title{
Measurement of the Potassium Content of Different Food Samples with High Purity Germanium Detectors
}

\author{
Iris Abt, Lucia Garbini, Oliver Schulz \\ Max-Planck-Institute for Physics, Munich, Germany \\ Email: garbini@mpp.mpg.de
}

Received 7 June 2016; accepted 18 July 2016; published 21 July 2016

Copyright (C) 2016 by authors and Scientific Research Publishing Inc.

This work is licensed under the Creative Commons Attribution International License (CC BY).

http://creativecommons.org/licenses/by/4.0/

(c) (i) Open Access

\begin{abstract}
Measurements of the potassium content of samples of food, performed with High Purity Germanium detectors, are presented in this paper. The potassium content was measured by identifying the $1460 \mathrm{keV}$ photons produced in the decay of the isotope ${ }^{40} \mathrm{~K}$. Samples were selected, for which a high potassium content was expected. The measurements confirmed the expectations qualitatively, but not always quantitatively. Especially the expected dependence of the potassium content of chocolate on the listed percentage of cacao could not be confirmed.
\end{abstract}

Keywords

HPGe Detectors, Gamma Spectroscopy, Food Testing

\section{Introduction}

Potassium is one of the elements responsible for natural radioactivity. It is also a very important mineral for human life. It is found in soil and water, and stored in food like beans, fruit and cacao. Samples of the same kind of food with different provenance allow studying the effect of the soil on the potassium content. The radioactive isotope ${ }^{40} \mathrm{~K}$ has a natural abundance of $0.012 \%$ [1]. In $10.6 \%$ of the cases, it decays via a $\beta^{+}$decay to a metastable state of ${ }^{40} \mathrm{Ar}$. In the isomeric transition to the ground state, ${ }^{40} \mathrm{Ar}$ emits a photon of $1460 \mathrm{keV}$, which can be identified by different kinds of detectors [2]. Measurements of the potassium content of food samples have been performed using Atomic Absorption Spectrometers [3], Fluorimeters [4], Sodium Iodide Based Detectors [5] [6] and High Purity Germanium (HPGe) Detectors [7]-[9].

HPGe detectors have an excellent energy resolution. Individual gamma lines up to several $\mathrm{MeV}$ can be measured with good efficiency, if the detectors are large enough. They are ideally suited to investigate natural ra- 
dioactivity in food. The purpose of this study is to measure the potassium content of different food samples and to evaluate the possible effects of soil and water. The method used is gamma ray spectroscopy with HPGe detectors.

The energy spectrum shown in Figure 1 was obtained with a potassium chloride (KCl) [10] calibration sample. The peak at $1460 \mathrm{keV}$, has a FWHM of $2.03 \mathrm{keV}$, demonstrating the excellent energy resolution of HPGe detectors. All peaks expected from natural radioactivity are suppressed due to a lead shield and the strength of the ${ }^{40} \mathrm{~K}$ peak. Clearly visible is the $511 \mathrm{keV}$ peak from pair production in the vicinity of the detector.

In Section 2, the experimental setup is described. A complete description of the preparation of the samples of food is found in Section 3. In Section 4, the method to extract the potassium content of the food samples from the spectra is described. The results of the analysis are shown and discussed in Section 5. The paper closes with some conclusions.

\section{Experimental Setup}

The experimental setup is shown in Figure 2. An HPGe Detector produced by Canberra is surrounded by a multilayer shield with a cavity to place the samples.

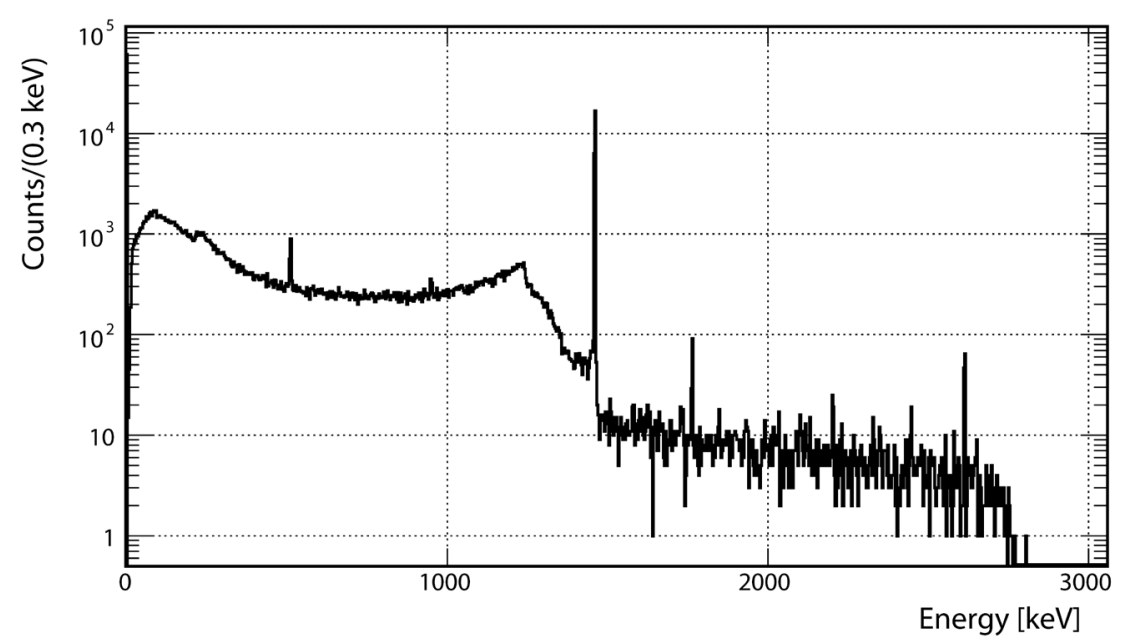

Figure 1. Energy spectrum obtained with a potassium chloride calibration sample in a shielded environment.

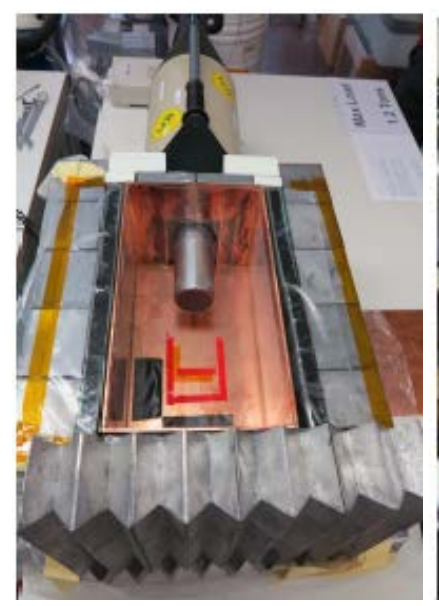

(a)

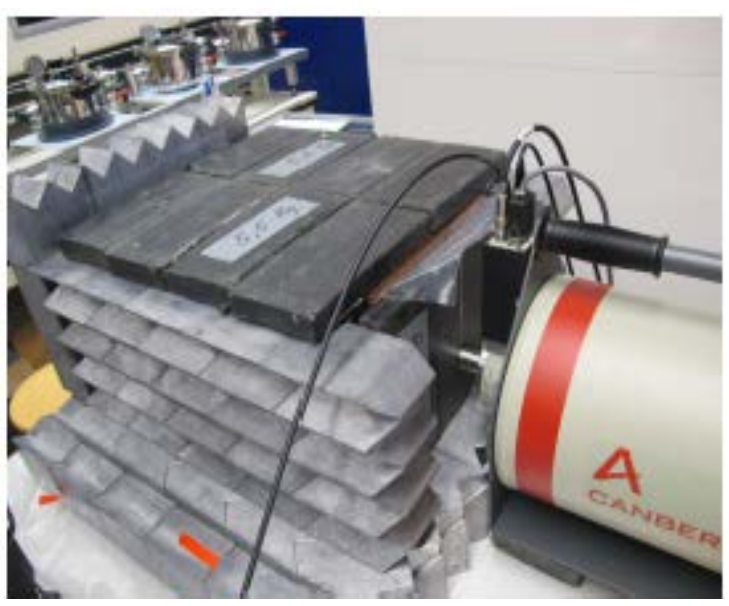

(b)

Figure 2. Experimental setup: the high purity germanium detector is surrounded by a multilayer shield leaving a cavity for the samples; (a) shows the open shield and (b) shows the closed shield. 


\subsection{High-Purity Germanium Detectors}

The measurements described in the paper were performed with two different HPGe detectors [2]: a Reverse Electrode coaxial Germanium Detector (REGe) and an eXtended Range Germanium detector (XtRa). Both are commercial detectors produced by Canberra. The REGe is a closed-end n-type detector while the XtRa is a closed-end p-type detector. Both have a very thin contact on the front surface and a carbon composite cryostat window. Both detectors were cooled with liquid nitrogen. The technical specifications for REGe and XtRa are listed in Table 1.

\subsection{Lead Shield}

In order to be sensitive to the low level of radioactivity in food, it is necessary to reduce the environmental background. This was done with a multilayer shield composed of an outer lead shield with a thickness of up to $10.5 \mathrm{~cm}$ and an inner copper shield with a thickness of $0.4 \mathrm{~cm}$ (see Figure 2).

Figure 3 shows a comparison between energy spectra obtained with three different shield configurations. The side walls alone already substantially reduced the high energy gamma lines, especially the Thallium line at 2.6 $\mathrm{MeV}$. This reduced also the Compton shoulder at medium energies. Figure 4 depicts the region around the ${ }^{40} \mathrm{~K}$ peak. The full shield reduced the ${ }^{40} \mathrm{~K}$ line by $95 \%$ and the continuous background in this region by $80 \%$.

\subsection{DAQ}

All the measurements presented in this paper were performed using a DGF Pixie-4 multichannel data acquisition system produced by XIA [11]. The software used to communicate with the Pixie-4 modules was a graphical user interface written using IGOR from Wavemetrics [12].

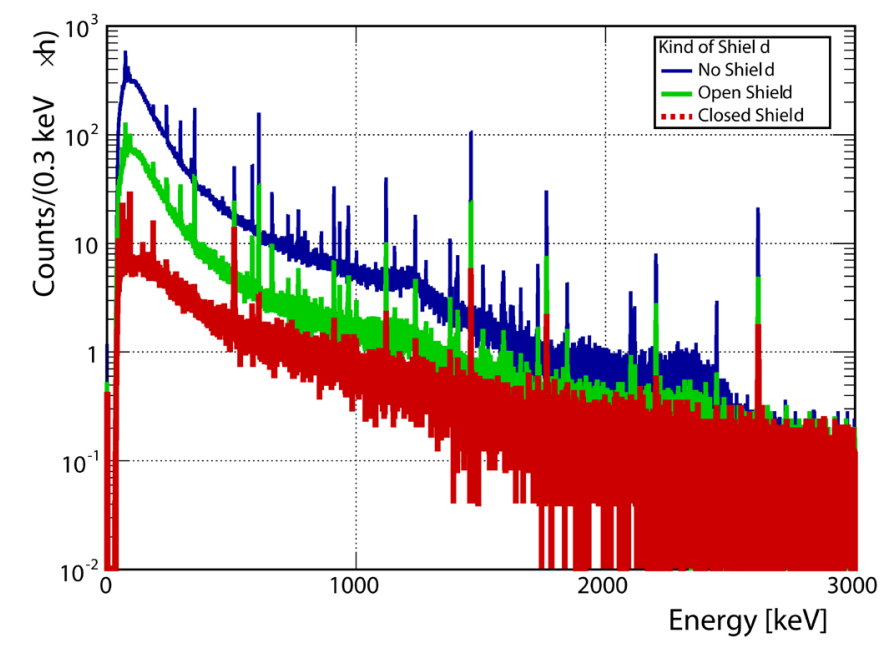

Figure 3. Comparison of background energy spectra obtained with three different shield configurations. Top: without shield; middle: with the open shield, i.e. lead bricks only as side walls; bottom with the closed shield.

Table 1. List of the specifications for the REGe and the XtRa detector.

\begin{tabular}{ccc}
\hline Type & REGe & XtRa \\
Geometry & n-type & p-type \\
Energy range & closed-end coaxial geometry \\
Recommended temperature & $3 \mathrm{keV}$ to several MeV \\
Energy resolution & $100 \mathrm{~K}$ \\
\hline
\end{tabular}




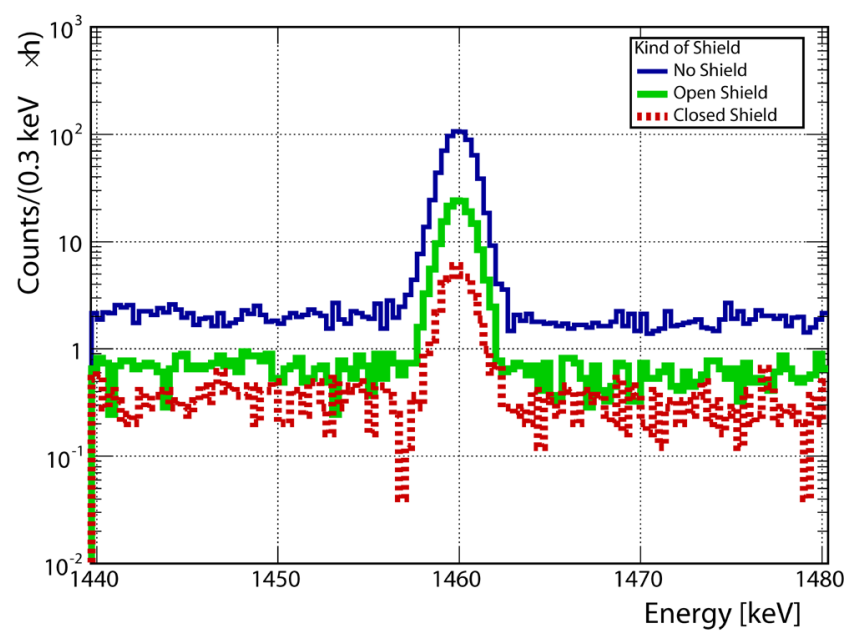

Figure 4. Comparison of background energy spectra obtained with three different shield configurations in the region of the ${ }^{40} \mathrm{~K}$ peak. Top: without shield; middle: with the open shield, i.e. lead bricks only as side walls; bottom with the closed shield.

\section{Data Taking}

Tables 2-5 provide an overview of all the food measurements discussed in this paper. The relevant quantities for each measurement are its lifetime and the mass of the sample. The date of the measurement is also given as the samples were purchased shortly before the measurements and variations with production time are probable.

The measurements listed in different tables were done with slightly different setups. A calibration measurement was done for each of these configurations. All samples were weighed to a precision of $0.1 \mathrm{~g}$. The samples were placed in plastic containers. The container and its relative position to the detector were the same for all the measurements in a given configuration to guarantee the same geometrical acceptance.

Figure 5 shows pictures of different samples as used in the measurements. The first phase of the study (see Table 2) focused on fruit and nuts (F_12). In addition, some chocolates (DC_12) were investigated. In the DC_12 subset the \% values indicate the cacao content of the dark chocolates as listed by the producer Lindt. Fruit and chocolate samples were cut in small pieces to fill the container as shown in Figure 5. The second and the third phases (see Table 3 and Table 4) focused on chocolate. The DC_13 and DC_14 subsets contain dark chocolates with different nominal cacao content produced by Vivani and Lindt, respectively. Using these samples, together with the DC_12 samples, the connection between the cacao percentage and the potassium content was investigated. The CC_13 and CC_14 subsets contain dark chocolate with the same nominal cacao content (75\%) but different places of origin of the cacao. Using these samples, the effect of the place of origin of the cacao on the potassium content was investigated. The chocolate samples listed in Table 3 and Table 4 were chopped in order to obtain a uniform distribution of the chocolate in the container. This was not done in phase one. However, the effect of chopping was measured to be below 5\% [13] and was neglected. The fourth phase (see Table 5) focused on legumes (L_14). Those were the samples for which the highest potassium content was expected. The effect of the self-absorption was estimated in a Monte Carlo study to be below $5 \%$ for the $\mathrm{KCl}$, i.e. for the highest density of all the samples, and therefore neglected.

\section{Analysis Method}

\subsection{Extraction of the Peak Area}

The number of counts attributed to ${ }^{40} \mathrm{~K}$ was obtained by fitting the peak with a function $F(E, \sigma, b)$ representing a skewed Gaussian plus a step function [14] [15]:

$$
F(E, \sigma)=A \cdot\left(1-F_{\text {skew }}\right) \cdot\left(\frac{1}{\sigma \sqrt{2 \pi}}\right) \exp \left(-\left(\frac{E-\mu}{\sqrt{2} \sigma}\right)^{2}\right)
$$


Table 2. List of measurements from summer 2012 using the XtRa detector: KCL_12 contains calibration measurements, F_12 contains measurements of fruit and nuts and DC_12 contains measurements of samples, DCN_12, of dark chocolate with N\% of cacao. Background measurements are listed in B_12.

\begin{tabular}{|c|c|c|c|c|c|}
\hline & ID & Sample & $\begin{array}{c}\text { Date } \\
{[\mathrm{dd} / \mathrm{mm} / \mathrm{yy}]}\end{array}$ & $\begin{array}{c}\text { Lifetime } \\
{[\mathrm{h}]}\end{array}$ & $\begin{array}{c}\text { Mass } \\
{[\mathrm{g}]}\end{array}$ \\
\hline & KCL_12 & KCL & $25 / 05 / 12$ & 2.79 & 820.3 \\
\hline \multirow{9}{*}{ F_12 } & F01_12 & Bananas & $30 / 05 / 12$ & 13.47 & 453.6 \\
\hline & F02_12 & Kiwis & $31 / 05 / 12$ & 3.02 & 416.3 \\
\hline & F03_12 & Almonds & $31 / 05 / 12$ & 13.42 & 278.1 \\
\hline & F04_12 & Strawberries & $01 / 06 / 12$ & 2.99 & 458.6 \\
\hline & F05_12 & Dried prunes & $01 / 06 / 12$ & 2.70 & 400.1 \\
\hline & F06_12 & Pistachios & 01/06/12 & 2.15 & 316.5 \\
\hline & F07_12 & Hazelnuts & 04/06/12 & 2.78 & 405.0 \\
\hline & F08_12 & Raisins & 04/06/12 & 2.71 & 469.9 \\
\hline & F09_12 & Dried apricots & $04 / 06 / 12$ & 1.72 & 594.4 \\
\hline \multirow{3}{*}{ DC_12 } & DC50_12 & Lindt 50\% & 05/06/12 & 4.43 & 392.9 \\
\hline & DC70_12 & Lindt 70\% & 05/06/12 & 2.56 & 401.1 \\
\hline & DC85_12 & Lindt 85\% & 05/06/12 & 13.87 & 400.2 \\
\hline \multirow{2}{*}{ B_12 } & B01_12 & Background & $29 / 05 / 12$ & 18.70 & - \\
\hline & B02_12 & Background & $01 / 06 / 12$ & 53.65 & - \\
\hline
\end{tabular}

Table 3. List of measurements from autumn 2013 using the XtRa detector: KCL_13 contains calibration measurements, DC_13 contains measurements of samples, DCN_13, of dark chocolate with N\% of cacao and CC_13 contains measurements of samples of dark chocolate of $75 \%$ of cacao with different places of origin. Background measurements are listed in B_13.

\begin{tabular}{|c|c|c|c|c|c|}
\hline & ID & Sample & $\begin{array}{c}\text { Date } \\
\text { [dd/mm/yy] }\end{array}$ & $\begin{array}{l}\text { Lifetime } \\
{[\mathrm{h}]}\end{array}$ & $\begin{array}{c}\text { Mass } \\
{[\mathrm{g}]}\end{array}$ \\
\hline & KCL_13 & KCL & 09/10/13 & 2.53 & 334.7 \\
\hline \multirow{3}{*}{ DC_13 } & DC71_13 & Vivani 50\% & $10 / 10 / 13$ & 3.81 & 198.8 \\
\hline & DC85_13 & Vivani 70\% & $11 / 10 / 13$ & 3.71 & 186.8 \\
\hline & DC92_13 & Vivani 85\% & $14 / 10 / 13$ & 4.37 & 157.8 \\
\hline \multirow{7}{*}{ CC_13 } & CC01_13 & Bonnat Ceylon & $15 / 10 / 13$ & 4.73 & 192.5 \\
\hline & CC02_13 & Bonnat Chuao & $16 / 10 / 13$ & 4.10 & 190.7 \\
\hline & CC03_13 & BonnatHacienda Rosario & 28/10/13 & 7.93 & 191.2 \\
\hline & CC04_13 & Bonnat Cote d'Ivoire & 29/10/13 & 3.61 & 195.0 \\
\hline & CC05_13 & Bonnat Ecuador & 29/10/13 & 3.81 & 196.3 \\
\hline & CC06_13 & Bonnat Trinidad and Tobago & $30 / 10 / 13$ & 6.39 & 200.2 \\
\hline & CC07_13 & Bonnat Madagascar & $31 / 10 / 13$ & 3.06 & 204.6 \\
\hline \multirow{2}{*}{ B_13 } & B01_13 & Background & 09/10/13 & 20.29 & - \\
\hline & B02_13 & Background & $14 / 10 / 13$ & 20.69 & - \\
\hline
\end{tabular}


Table 4. List of measurements from summer 2014 using the REGe detector: KCL_14 contains calibration measurements, DC_14 contains measurements of samples, DCN_14, of dark chocolate with N\% of cacao and CC_14 contains measurements of samples of dark chocolate of $75 \%$ of cacao with different places of origin.Background measurements are listed in B_14.

\begin{tabular}{|c|c|c|c|c|c|}
\hline & ID & Sample & $\begin{array}{c}\text { Date } \\
\text { [dd/mm/yy] }\end{array}$ & $\begin{array}{c}\text { Lifetime } \\
{[\mathrm{h}]}\end{array}$ & $\begin{array}{c}\text { Mass } \\
{[\mathrm{g}]}\end{array}$ \\
\hline & KCL01_14 & KCL & $13 / 05 / 14$ & 2.16 & 817.5 \\
\hline \multirow{4}{*}{ DC_14 } & DC50_14 & Lindt 50\% & $22 / 05 / 14$ & 4.02 & 450.2 \\
\hline & DC70_14 & Lindt $70 \%$ & $02 / 06 / 14$ & 3.79 & 499.3 \\
\hline & DC85_14 & Lindt $85 \%$ & $15 / 05 / 14$ & 2.63 & 430.8 \\
\hline & DC90_14 & Lindt 90\% & $13 / 05 / 14$ & 4.37 & 429.9 \\
\hline \multirow{8}{*}{ CC_14 } & CC01_14 & Bonnat Ceylon & 09/06/14 & 3.70 & 471.5 \\
\hline & CC02_14 & Bonnat Chuao & 05/06/14 & 3.60 & 450.7 \\
\hline & CC03_14 & Bonnat Hacienda Rosario & $11 / 06 / 14$ & 3.70 & 466.5 \\
\hline & CC04_14 & Bonnat Cote d'Ivoire & $10 / 06 / 14$ & 3.64 & 466.0 \\
\hline & CC05_14 & Bonnat Ecuador & $06 / 06 / 14$ & 3.66 & 470.8 \\
\hline & CC06_14 & Bonnat Trinidad and Tobago & 09/06/14 & 3.77 & 462.2 \\
\hline & CC07_14 & Bonnat Madagascar & $05 / 06 / 14$ & 3.67 & 469.0 \\
\hline & CC08_14 & Bonnat Puerto Cabello & $05 / 06 / 14$ & 3.79 & 451.7 \\
\hline \multirow{7}{*}{ B_14 } & B01_14 & Background & $06 / 05 / 14$ & 39.97 & - \\
\hline & B02_14 & Background & $13 / 05 / 14$ & 40.06 & - \\
\hline & B03_14 & Background & $22 / 05 / 14$ & 87.26 & - \\
\hline & B04_14 & Background & $02 / 06 / 14$ & 63.13 & - \\
\hline & B05_14 & Background & 05/06/14 & 14.83 & - \\
\hline & B06_14 & Background & 09/06/14 & 14.71 & - \\
\hline & B07_14 & Background & $10 / 06 / 14$ & 14.97 & - \\
\hline
\end{tabular}

Table 5. List of measurements from summer 2014 using the REGe detector: KCL_14 contains calibration measurements done with $\mathrm{KCl}, \mathrm{L} \_14$ contains measurements of samples of legumes. Background measurements are listed in B_14.

\begin{tabular}{cccccc}
\hline & ID & Sample & $\begin{array}{c}\text { Date } \\
{[\mathrm{dd} / \mathrm{mm} / \mathrm{yy}]}\end{array}$ & $\begin{array}{c}\text { Lifetime } \\
{[\mathrm{h}]}\end{array}$ & $\begin{array}{c}\text { Mass } \\
{[\mathrm{g}]}\end{array}$ \\
\hline & KCL02_14 & KCL & $08 / 05 / 14$ & 1.86 & 1200.1 \\
\hline \multirow{2}{*}{ L_14 } & L01_14 & White beans & $26 / 05 / 14$ & 2.57 & 900.0 \\
& L02_14 & Green peas & $26 / 05 / 14$ & 3.31 & 900.0 \\
& L03_14 & Red lentils & $27 / 05 / 14$ & 12.5 & 900.0 \\
\hline \multirow{2}{*}{ B_14 } & B01_14 & Background & $26 / 05 / 14$ & 94.02 & - \\
& B02_14 & Background & $29 / 05 / 14$ & 28.07 & - \\
\hline
\end{tabular}

$$
\begin{gathered}
+\frac{A \cdot F_{\text {skew }}}{2 b} \cdot \exp \left(\frac{E-\mu}{b}+\frac{\sigma^{2}}{2 b^{2}}\right) \cdot\left(1-\operatorname{erf}\left(\frac{E-\mu}{\sqrt{2} \sigma}+\sigma \sqrt{2} b\right)\right) \\
+\frac{I}{2} \operatorname{erfc}\left(\frac{E-\mu}{\sqrt{2} \sigma}\right)
\end{gathered}
$$



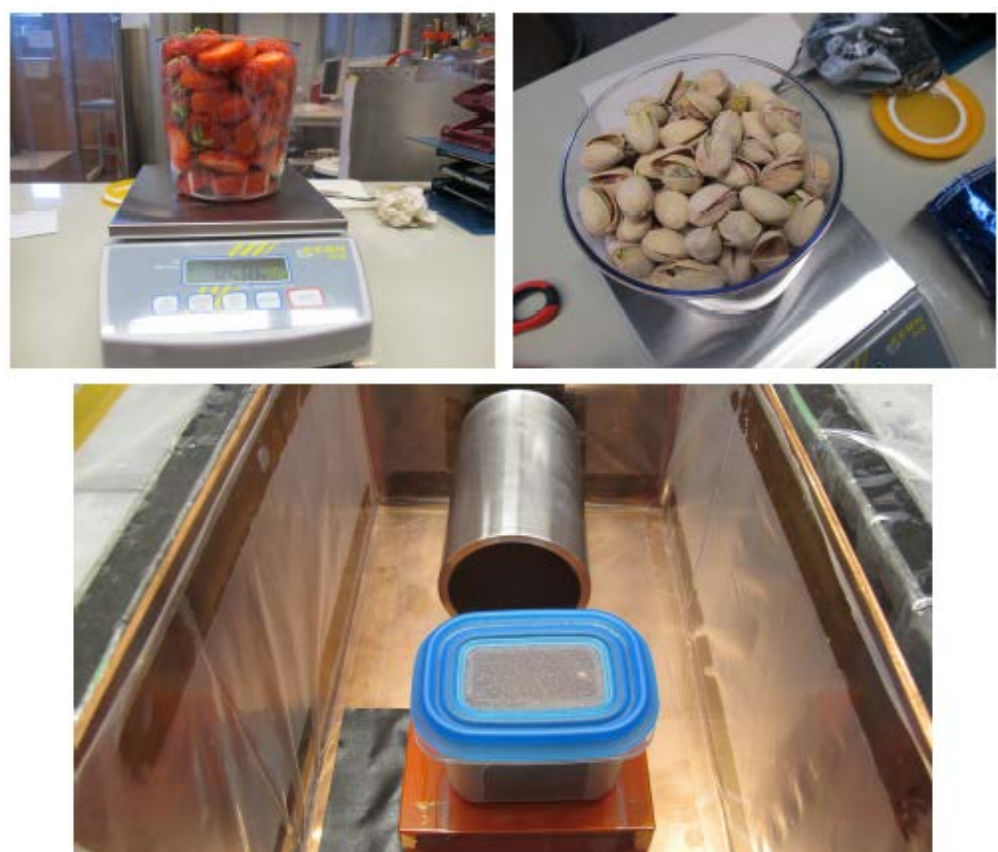

Figure 5. Pictures of strawberries, pistachios and chocolate as used in the measurements.

(1a) describes the Gaussian component of the peak, where:

$E$ is the energy;

$A$ is the area underneath the peak;

$\sigma$ is the standard deviation of the Gaussian;

$\mu$ is the center of the peak;

(1b) represents an exponentially modified Gaussian which describes the tail in the lower energy side of the peak, where:

$F_{\text {skew }}$ is the skewness factor;

$b=W_{\text {skew }} \sigma$ is the relaxation time of the exponential component;

(1c) represents the step function which describes the Compton scattering component, where:

$I$ is the amplitude of the step function.

The uncertainty on A was obtained from the fitting procedure as implemented in the ROOT [16] analysis framework. Figure 6 shows an example of a fit performed for the chocolate sample CC06_14 listed in Table 4.

\subsection{Background Subtraction}

The lead shield does not completely remove the effect of the environmental potassium. The number of gammas coming from the sample was calculated as:

$$
A_{S}^{\text {sample }}=A_{S+B K G}^{\text {sample }}-A_{B K G}^{\text {sample }}
$$

As the environmental background varies over time it is important to not only perform long enough background measurements, but to do them also in temporal proximity with the sample measurements.

\subsection{Detector Calibration}

The calibration of each setup was performed with $\mathrm{KCl}$. The calibration factor was defined as:

$$
\epsilon_{K C l}=\frac{C_{K}^{K C l}\left(\frac{\mathrm{mg}}{100 \mathrm{~g}}\right)}{A_{S}^{K C l}}
$$




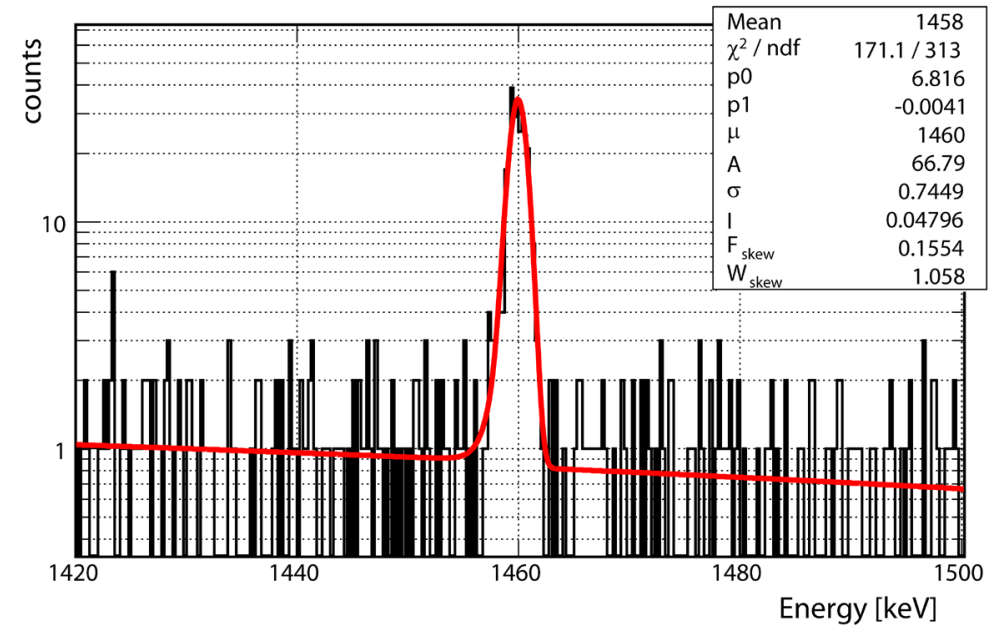

Figure 6. Energy spectrum (histogram) of the chocolate sample CC06_14 from Table 4 around the ${ }^{40} \mathrm{~K}$ peak and the result of the fit performed using the function in Equation 1 plus a first order polynomial represented by the parameters p0 and p1 (line).

where $C_{K}^{K C l}$ is the potassium content in the $K C l$ sample in mg per $100 \mathrm{~g}$, as specified in its data sheet, and $A_{S}^{K C l}$ is the area underneath the ${ }^{40} \mathrm{~K}$ peak in the $\mathrm{KCl}$ energy spectrum after background subtraction. The uncertainty on $\epsilon_{K C l}$ can be asymmetric. It is evaluated varying $C_{K}^{K C l}$ and $A_{S}^{K C l}$ according to their uncertainties, in order to obtain the one sigma deviations $\Delta_{s y s}^{+}\left(\epsilon_{K C l}\right)$ and $\Delta_{s y s}^{-}\left(\epsilon_{K C l}\right)$. These uncertainties are taken as systematic uncertainties on the potassium content of the food samples.

\subsection{Extraction of Potassium Content}

Using the calibration factor, $\epsilon_{K C l}$, the potassium content in mg per $100 \mathrm{~g}, C_{K}$, was calculated as:

$$
C_{K}\left(\frac{\mathrm{mg}}{100 \mathrm{~g}}\right)=\frac{A_{\mathrm{s}}^{\text {food }}}{m_{\text {food }}} \cdot \epsilon_{\mathrm{KCl}}=F_{\text {food }} \cdot \epsilon_{\mathrm{KCl}}
$$

where $A_{s}^{\text {food }}$ from Equation 2 is the area underneath the ${ }^{40} \mathrm{~K}$ peak measured for the food sample and $m_{\text {food }}$ is its mass. The statistical uncertainty is calculated from the fit uncertainty on $A_{S}^{\text {food }}$ and the uncertainty of $0.1 \mathrm{~g}$ on $m_{\text {food }}$. The systematic uncertainty results from the uncertainty on $o K C l$ (see Secition 4.3). The uncertainties are computed as asymmetric, but in many cases are symmetric and quoted as $\Delta_{\text {stat }}$ and $\Delta_{\text {sys }}$.

\section{Results and Discussion}

The measured potassium content, $C_{K}^{\text {meas }}$, for all samples listed in Tables 2-5 are given in Tables 6-9. Also given are expectations, $C_{K}^{\text {expec }}$ [17], and statistical $\left(\Delta_{\text {stat }}\right)$ and systematic $\left(\Delta_{\text {sys }}\right)$ uncertainties. The statistical uncertainties dominate. The expected values [17] are reported without uncertainties.

Figure 7 shows the F_12 results on fruit and nuts listed in Table 6. The agreement between the expected and measured values is good for fresh fruit like bananas, kiwis and strawberries. The disagreement observed for processed food points to the influence of the processing techniques. The nuts show a potassium content lower than expected, while the dried fruit shows a higher one. The more dehydrated the fruit, the higher is the relative potassium content. The ratios between expectation and measurement are not uniform but the trends are very clear.

The subset DC_12 of Tables 6-8 list the results for chocolate. Given the cacao content, C (\%), of a bar of chocolate of $100 \mathrm{~g}$, the expected potassium content is calculated as:

$$
C_{K}^{\text {bar }}\left(\frac{\mathrm{mg}}{100 \mathrm{~g}}\right)=C_{K}^{\text {cacao }}\left(\frac{\mathrm{mg}}{100 \mathrm{~g}}\right) \cdot C(\%)
$$


Table 6. List of the expected ( $C_{K}^{\text {expected }}$ ) and measured $\left(C_{K}^{\text {meas }}\right)$ potassium content of the fruit, nuts and chocolates listed in Table 2. The measured value is quoted together with the statistical uncertainty, $\boldsymbol{\Delta}_{\text {stat }}$, the systematic uncertainty, $\boldsymbol{\Delta}_{\text {sys }}$, and their quadratic sum $\boldsymbol{\Delta}_{\text {tot }}$.

\begin{tabular}{ccccccc}
\hline & ID & $C_{K}^{\text {expected }}\left(\frac{\mathrm{mg}}{100 \mathrm{~g}}\right)[17]$ & $C_{K}^{\text {meas }}\left(\frac{\mathrm{mg}}{100 \mathrm{~g}}\right)$ & $\boldsymbol{\Delta}_{\text {stat }}$ & $\boldsymbol{\Delta}_{\text {sys }}$ & $\boldsymbol{\Delta}_{\text {tot }}$ \\
\hline & F01_12 & 358 & 357 & 25 & 2 & 25 \\
& F02_12 & 312 & 312 & 16 & 2 & 16 \\
& F03_12 & 733 & 619 & 41 & 3 & 41 \\
& F04_12 & 153 & 184 & 2 & 1 & 3 \\
& F05_12 & 300 & 766 & 16 & 4 & 16 \\
& F06_12 & 1025 & 733 & 54 & 4 & 38 \\
& F07_12 & 680 & 1134 & 58 & 3 & 54 \\
& F08_12 & 746 & 1315 & 65 & 7 & 59 \\
& F09_12 & 1162 & 417 & 40 & 2 & 66 \\
\hline
\end{tabular}

Table 7. List of the expected ( $C_{K}^{\text {expected }}$ ) and measured ( $C_{K}^{\text {meas }}$ ) potassium content of the samples of chocolate listed in Table 3. Other details as in Table 6.

\begin{tabular}{rlccccc}
\hline & ID & $C_{K}^{\text {expected }}\left(\frac{\mathrm{mg}}{100 \mathrm{~g}}\right)[17]$ & $C_{K}^{\text {meas }}\left(\frac{\mathrm{mg}}{100 \mathrm{~g}}\right)$ & $\boldsymbol{\Delta}_{\text {stat }}$ & $\boldsymbol{\Delta}_{\text {sys }}$ & $\boldsymbol{\Delta}_{\text {tot }}$ \\
\hline \multirow{2}{*}{ DC_13 } & 1082 & 726 & 35 & 6 & 36 \\
& DC71_13 & 1296 & 832 & 44 & 7 & 44 \\
& DC85_13 & 1403 & 642 & 106 & ${ }_{-7}^{+6}$ & 106 \\
\hline \multirow{2}{*}{ CC_13 } & 1143 & 590 & 85 & 5 & 85 \\
& CC01_13 & 1143 & 814 & 41 & 7 & 42 \\
& CC02_13 & 1143 & 660 & 52 & 6 & 53 \\
& CC03_13 & 1143 & 529 & 93 & -5 & 93 \\
\hline
\end{tabular}

where $C_{K}^{\text {cacao }}\left(\frac{\mathrm{mg}}{100 \mathrm{~g}}\right)$ is the potassium content of pure cacao. Potassium is assumed to be contained only in cacao. Figure 8 shows the correlation between the nominal content of cacao and the measured potassium content for samples produced by Lindt (DC_12 and DC_14, purchased in summer 2012 and summer 2014 respectively) and Vivani (DC_13), purchased in autumn 2013. The expected potassium content (Equation (5)) are also shown. Both Lindt chocolates have higher potassium content for higher percentage of cacao. However, the proportionality is not as expected: for lower (higher) nominal cacao content the measured potassium content is lower (higher) than expected. For Vivani chocolates, the potassium content is basically independent of the nominal \% of cacao. This behavior could point to inaccurately quoted percentages of cacao or to production techniques influencing the potassium content of the product. 


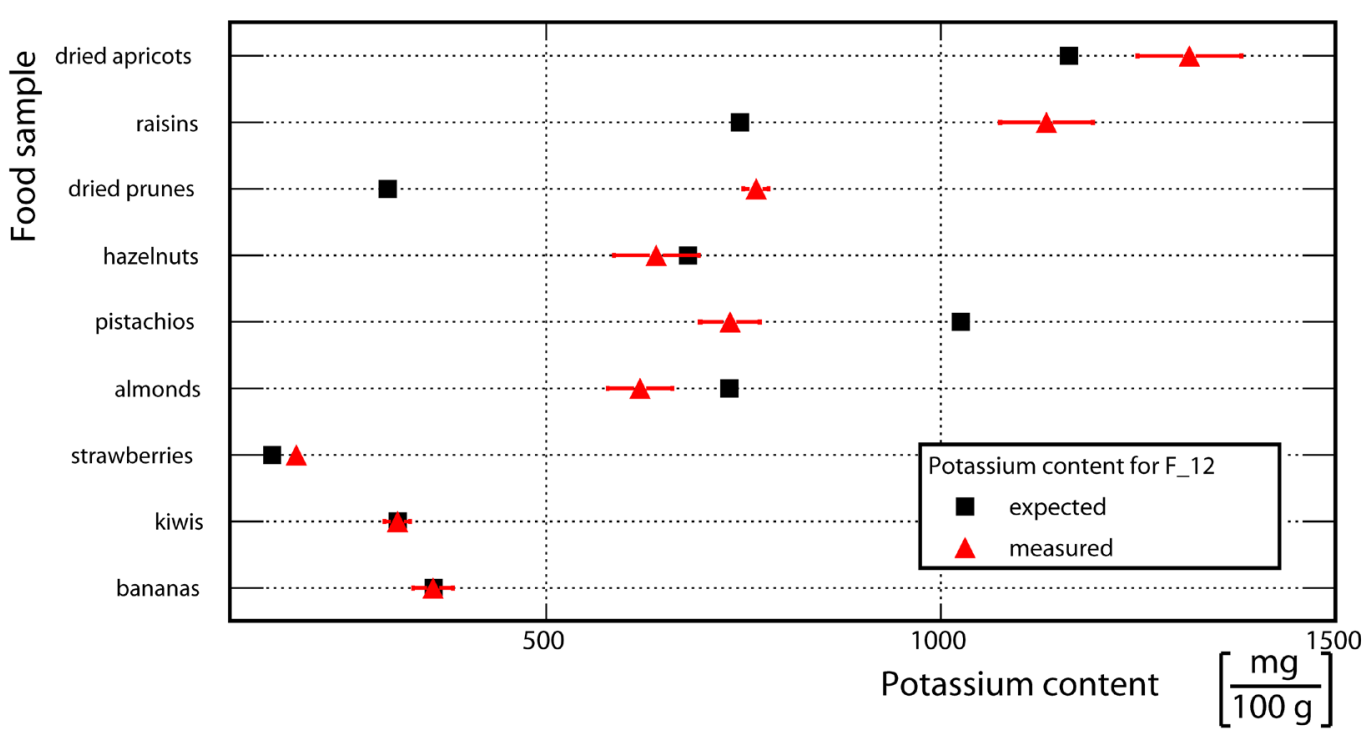

Figure 7. Comparison between the expected (squares) and the measured (triangles) values of the potassium content of selected fruit and nuts as listed in Table 6.

Table 8. List of the expected ( $C_{K}^{\text {expected }}$ ) and measured ( $C_{K}^{\text {meas }}$ ) potassium content of the samples of chocolate listed in Table 4. Other details as in Table 6.

\begin{tabular}{|c|c|c|c|c|c|c|c|}
\hline & ID & $C_{K}^{\text {expected }}$ & $\left(\frac{\mathrm{mg}}{100 \mathrm{~g}}\right)$ [17] & $C_{\kappa}^{\text {meas }}\left(\frac{\mathrm{mg}}{100 \mathrm{~g}}\right)$ & $\boldsymbol{\Delta}_{\text {stat }}$ & $\boldsymbol{\Delta}_{s y s}$ & $\boldsymbol{\Delta}_{\text {tot }}$ \\
\hline \multirow{4}{*}{ DC_14 } & DC50_14 & & 762 & 394 & 22 & 4 & 23 \\
\hline & DC70_14 & & 1067 & 680 & 61 & 6 & 62 \\
\hline & DC85_14 & & 1296 & 1498 & 25 & 14 & 29 \\
\hline & DC90_14 & & 1372 & 1705 & 110 & 16 & 111 \\
\hline \multirow{8}{*}{ CC_14 } & CC01_14 & & 1143 & 619 & 49 & 6 & 49 \\
\hline & CC02_14 & & 1143 & 585 & 66 & 5 & 66 \\
\hline & CC03_14 & & 1143 & 465 & 110 & 4 & 110 \\
\hline & CC04_14 & & 1143 & 528 & 112 & 5 & 112 \\
\hline & CC05_14 & & 1143 & 629 & 113 & 6 & 113 \\
\hline & CC06_14 & & 1143 & 591 & 61 & 5 & 61 \\
\hline & CC07_14 & & 1143 & 652 & 65 & 6 & 65 \\
\hline & CC08_14 & & 1143 & 688 & 23 & 6 & 24 \\
\hline
\end{tabular}

Table 9. List of the expected ( $C_{K}^{\text {expected }}$ ) and measured ( $C_{K}^{\text {meas }}$ ) potassium content of the legumes listed in Table 5. Other details as in Table 6.

\begin{tabular}{ccccccc}
\hline & ID & $C_{\kappa}^{\text {expected }}\left(\frac{\mathrm{mg}}{100 \mathrm{~g}}\right)$ & $C_{K}^{\text {meas }}\left(\frac{\mathrm{mg}}{100 \mathrm{~g}}\right)$ & $\boldsymbol{\Delta}_{\text {stat }}$ & $\boldsymbol{\Delta}_{\text {sys }}$ & $\boldsymbol{\Delta}_{\text {tot }}$ \\
\hline \multirow{2}{*}{ L_14 } & L01_14 & 1795 & 1630 & 101 & ${ }^{+16}$ & 103 \\
& L02_14 & 244 & 1064 & 77 & 11 & 78 \\
& L03_14 & 668 & 1100 & 21 & 11 & 24 \\
\hline
\end{tabular}




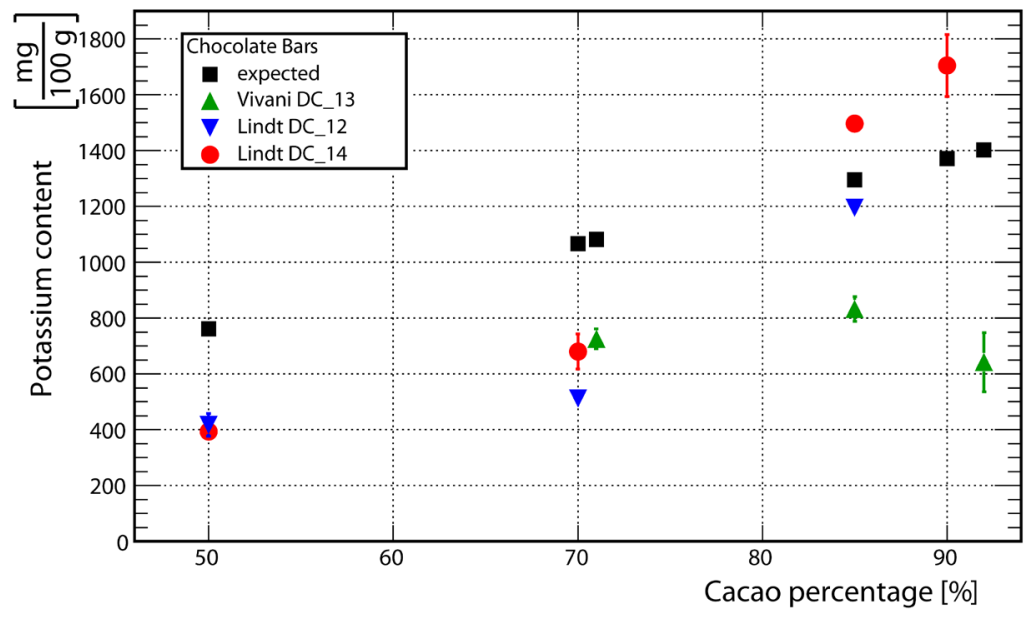

Figure 8. Correlation between the measured potassium content and the quoted percentage of cacao in bars of chocolate for different brands: squares show the expected potassium content while up triangles show Vivani samples from autumn 2013, down triangles Lindt samples from summer 2012 and circles Lindt samples from summer 2014 (see Tables 6-8).

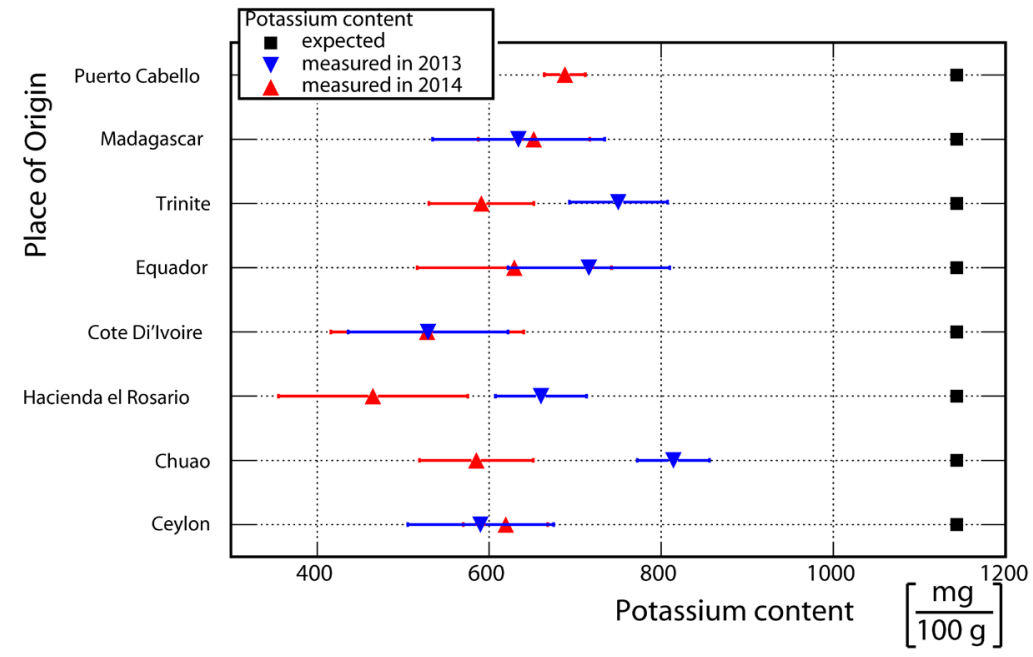

Figure 9. Comparison between the expected (squares) and the measured (triangles) values of the potassium content in bars of dark-chocolate (75\% of cacao), produced by Bonnat, with cacao coming from different countries as listed in Table 7 and Table 8. No measurement for Puerto Cabello was performed in autumn 2013.

Figure 9 shows a comparison between the expected and the measured potassium content in bars of chocolate produced by Bonnat with cacao coming from different countries. Measurements for each place of origin were performed with two slightly different setups and using two samples of chocolate (75\% of cacao) purchased in different years. The results are from autumn 2013 (CC_13 in Table 7) and from summer 2014 (CC_14 in Table 8). The two sets of measurements agree within the uncertainties. However, the measurements show a potassium content significantly lower than expected. This behavior could point either to a cacao content lower than declared or to specific production techniques that might influence the potassium content. No significant variations due to the place of origin are observed.

Table 9 shows the results for legumes. Figure 10 shows the comparison between the expected and the measured potassium content. Both, red lentils and green peas, have a potassium content higher than expected, while the white beans autumn short. However, the white beans still have the highest measured potassium content. 


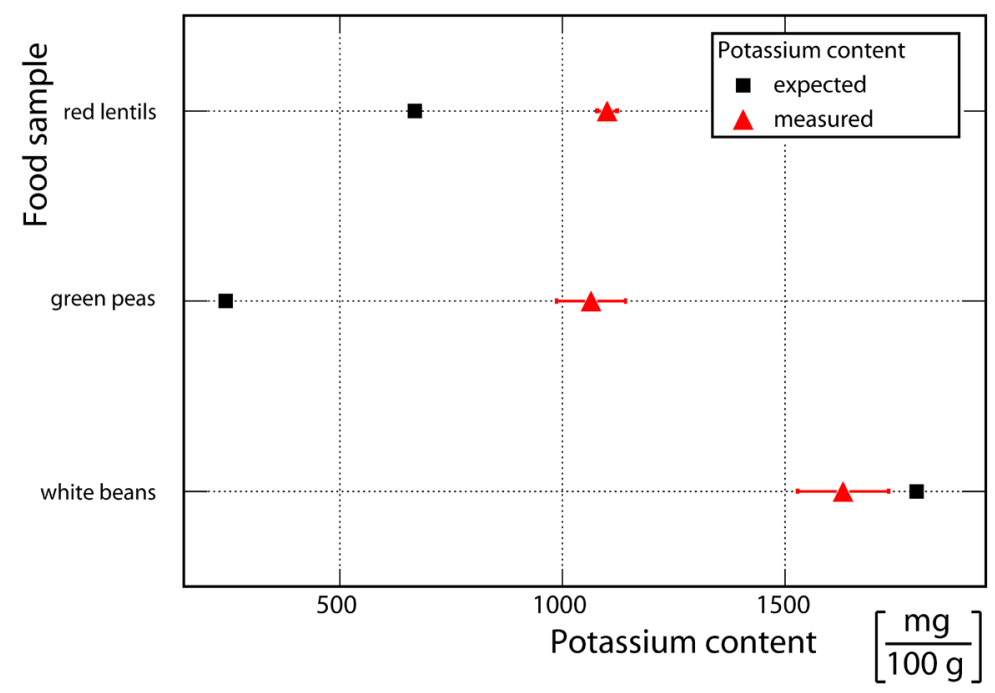

Figure 10. Comparison between the expected (squares) and the measured (triangles) values of the potassium content for different kinds of legumes (see Table 9).

\section{Conclusion}

In this paper, a simple and clean method to measure the potassium content of samples of food with germanium detectors was presented. The results verify the high potassium content expected for fruit, nuts, chocolate and legumes. However, the expectations are not always met quantitatively. Especially the expected dependence of the potassium content of chocolate on the listed percentage of cacao could not be confirmed. No dependence on the origin of the samples could be established with statistical significance. The highest measured potassium contents are $1705 \mathrm{mg} / 100 \mathrm{~g}$ from dark chocolate with $90 \%$ of cacao and $1630 \mathrm{mg} / 100 \mathrm{~g}$ from white beans. Eating either $100 \mathrm{~g}$ of $90 \%$ cacao chocolate or $100 \mathrm{~g}$ of white beans provide approximately $50 \%$ of the daily recommendation of $3.5 \mathrm{~g}$ [18] of potassium.

\section{Acknowledgements}

We thank the entire GeDet group of the Max-Planck-Institute for Physics in Munich for their help and technical support. We would like specially to thank the students A. Burger, M. Duda and M. Schuster who helped carrying out some of the measurements. Part of the material presented in this paper is based upon work supported by the LMU-Mentoring founding program (autumn 2013).

\section{References}

[1] (2015) Potassium Isotopes. www.chemicalelements.com/elements/k.html

[2] Knoll, G.F. (2000) Radiation Detection and Measurement. 3rd Edition.

[3] Vaessen, H.A.M.G. and van de Kamp, C.G. (1989) Sodium and Potassium Assay of Foods and Biological Substrates by Atomic Absorption Spectroscopy (AAS). Pure and Applied Chemistry, 61, 113-120. http://dx.doi.org/10.1351/pac198961010113

[4] Emumejaye, K. (2012) Determination of the Potassium 40 Concentration in Some Powdered Milk Samples Consumed In Delta State, Nigeria. IOSR Journal of Applied Physics (IOSR-JAP), 2, 8-12.

[5] Hoeling, B., Reed, D. and Siegel, P.B. (1999) Going Bananas in the Radiation Laboratory. American Association of Physics Teachers, 67, 440-442.

[6] Escareno-Juarez, E. and Vega-Carrillo, H.R. (2012) K-40 Measurement to Determine the Total Potassium Content. Revista Mexicana de Fisica, 58, 211-214.

[7] Acquaha, G.F. and Pokoo-Aikinsb, M. (2013) Foodstuffs and Cancer: Analysis of Radionuclides and Its Radiation Levels in Common Ghanaian Maize. International Journal of Sciences: Basic and Applied Research (IJSBAR), 12.

[8] Abbasisiar, F. (2006) IAEA, INIS. 
[9] (2014) ORTEC: Food Monitoring Notes.

[10] (2014) PanReac AppliChem A1362 Potassium Chloride Specification.

[11] 4-Channel 75 MHz PXI Digital Spectrometer Data Sheet.

[12] (2015) Wavemetrics. www.wavemetrics.com

[13] Schuster, M. (2014) Analysis of Potassium Induced Radioactivity in Chocolates Based on Spectra Taken with High Purity Germanium Detectors. Bachelor Thesis.

[14] Phillips, G.W. and Marlow, K.W. (1976) Automatic Analysis of Gamma-Ray Spectra from Germanium Detectors. Nuclear Instruments and Methods, 137, 525-536. http://dx.doi.org/10.1016/0029-554X(76)90472-9

[15] Mcnelles, L.A. and Campbell, J.L. (1975) Analytic Approximations to Peak Shapes Produced by Ge(Li) and Si(Li) Spectrometers. Nuclear Instruments and Methods, 127, 73-81. http://dx.doi.org/10.1016/0029-554X(75)90304-3

[16] (2015) ROOT Data Analysis Framework. http://root.cern.ch/drupal/

[17] (2014) National Nutrient Database for Standard Reference Release 27.

[18] (2012) World Health Organization, Potassium Intake for Adults and Children.

\section{Submit or recommend next manuscript to SCIRP and we will provide best service for you:}

Accepting pre-submission inquiries through Email, Facebook, LinkedIn, Twitter, etc. A wide selection of journals (inclusive of 9 subjects, more than 200 journals)

Providing 24-hour high-quality service

User-friendly online submission system

Fair and swift peer-review system

Efficient typesetting and proofreading procedure

Display of the result of downloads and visits, as well as the number of cited articles

Maximum dissemination of your research work

Submit your manuscript at: http://papersubmission.scirp.org/ 